\title{
Assessment of several spectral indices derived from multi-temporal Landsat data for fire occurrence probability modelling
}

\author{
F. Javier Lozano*, Susana Suárez-Seoane, Estanislao de Luis \\ Área de Ecología, Fac. Cc. Biológicas y Ambientales, 24071 Campus de Vegazana, Universidad de León, León, Spain
}

Received 20 June 2006; received in revised form 4 October 2006; accepted 7 October 2006

\begin{abstract}
A detailed understanding of the spatial patterns of burning is valuable for managing biodiversity and ecosystems. This research assesses the performance of several spectral indices derived from Landsat data when modelling fire occurrence probability by means of logistic regression. Normalized Difference Vegetation Index (NDVI), Normalized Difference Moisture Index (NDMI), Normalized Burn Ratio (NBR) and the greenness and wetness components of the Tasseled Cap Transformation were tested. Landscape variables (topography, accessibility and structural vegetation) were also included as predictors in models development. Although fire risk is closely related to weather and vegetation status at a given time, it is also strongly linked to fire history, and changes in predictor values in years previous to the fire were events also considered. The models generated correctly classified about $70 \%$ of the validation data set. The inclusion of pre-fire spectral indices improved models ability to predict fire occurrence. Although the NBR-based model was the most accurate, TCWetness and NDVI-based models showed similar results, while TCGreenness performed worst. Models with no spectral indices described the fire-proneness of the landscape structure, while the inclusion of spectral indices improved the recognition of particular spatial conditions. Slope and distance to the nearest path were also identified as valuable predictors. All the models identified the main fire risk zones in the study area. Their integration into a single, integrated model properly described fire-proneness and is suggested to be a valuable tool for the identification and management of fire risk. The method used is simple, describes the key variables and spatial pattern of the fire regime and is suited to operational use in Mediterranean ecosystems.
\end{abstract}

(C) 2006 Elsevier Inc. All rights reserved.

Keywords: Fire risk; Static models; Vegetation characterization; Logistic regression; Fire history

\section{Introduction}

Ecological systems are dynamic and, in addition to successional processes, disturbance is an important force for change. Fire is one of the main disturbances at local, regional and global scales, determining biogeochemical dynamics and the successional status of ecosystems. It directly affects species diversity (Brockway \& Lewis, 1997; Calvo et al., 2002a,b), can increase fragmentation and alter landscape functioning (Lloret et al., 2002). In the Mediterranean Basin, natural and human-caused fires have driven landscape change for thousands of years (Trabaud et al., 1993). However, changing social and economic conditions have led to a change in fire regimes during recent decades (Pausas \& Ramos, 2004; Terradas et al., 1998). Because

\footnotetext{
* Corresponding author.

E-mail address: javierl@unileon.es (F.J. Lozano).
}

the effects of fire vary with spatial patterns of burning, they must be assessed in a spatially explicit way, so that accurate maps can be provided to scientists, managers and decision makers, especially when dealing with patchy landscapes.

Recent higher environmental awareness and technological and scientific advances have resulted in an increase in the availability of resources and tools for fire management and fighting. Fire risk and damage modelling are valuable tools, but data collection to feed these models is costly in terms of money, time and human resources. Remote sensing has proved to be a solution for this problem. There are several examples of remotely sensed data applied to fire events: (i) to characterize forest fuels (Andersen et al., 2005; Jia et al., 2006); (ii) for fire monitoring (Chand et al., 2006; Dennison et al., 2006), (iii) to map the fire scars at local (Koutsias \& Karteris, 2000) or global scale (Justice et al., 2002; Stroppiana et al., 2000); (iv) to assess the effects of the events (Díaz-Delgado et al., 2002; Liu et al., 
2005). Spectral indices, obtained by a combination of data acquired at different spectral regions, are widely used for vegetation monitoring and assessment in fire-related studies (e.g. Chuvieco et al., 2004; López et al., 2002; Mbow et al., 2004). However, when dealing with vegetation monitoring or characterization, there still remains certain confusion when choosing the most suitable index to be used depending on the study objectives.

Although the defined spectral indices are numerous, some of them have been widely applied for different purposes and study sites. The Normalized Difference Vegetation Index or NDVI (Rouse et al., 1973) separates green vegetation from other surfaces because the chlorophyll of green vegetation absorbs red light for photosynthesis and reflects near-infrared (NIR) wavelengths due to scattering caused by internal leaf structure (Tucker, 1979). The Normalized Difference Moisture Index or NDMI (Jin \& Sader, 2005; Wilson \& Sader, 2002) is similarly calculated, but uses shortwave-infrared (SWIR) instead of red wavelengths. The reduction of reflectance of the SWIR as compared to the NIR is due to the absorption of water in tissues, so that index value can be used as an estimation of water content in the vegetation. It is also related to vegetation structure and cover, as well as to emissivity and energy balance (McDonald et al., 1998). The Normalized Burn Ratio or NBR (Key \& Benson, 1999) is widely used nowadays for fire mapping. It attempts to maximize reflectance changes due to fire events, since after fires the NIR reflectance decreases and mid-infrared (MIR) reflectance increases in comparison to prefire values (Clark, 2000; Key \& Benson 1999; López García \& Caselles, 1991; White et al., 1996). The Tasseled Cap Transformation (Crist \& Cicone, 1984) is another index commonly used. Tasseled Cap Greenness (TCG) corresponds to absorption in the visible bands and reflectance in the NIR band (Patterson \& Yool, 1998). The "wetness" feature (TCW) contrasts the visible and NIR with the SWIR and MIR bands (Crist \& Cicone, 1984) and it is useful for vegetation applications (Wilson \& Sader, 2002). All the aforementioned indices add crucial information to the static model of fire probability, encompassing vegetation features such as health, structure, biomass or moisture content.

Logistic regression has been used for fire modelling following various approaches. Among other studies, research by Vega García et al. (1995), Cardille et al. (2001) and Preisler et al. (2004) concluded that logistic regression models are valuable tools for predicting fire. In spite of their advantages, there are few studies combining spectral indices and logistic regression for fire modelling purposes. Rollings et al. (2004) used band digital numbers and derived spectral indices, among other predictors, to map fire regime and fuels. The aforementioned studies suggest the utility of further assessments combining spectral indices and logistic regression for fire modelling purposes.

Another gap of knowledge, when dealing with fire risk modelling, is related with the use of fire history. Although fire occurrence probability is closely related with weather and vegetation status at a given time, it is also strongly linked with recent fire events. Few efforts have considered this approach, as de la Riva et al. (2004) who spatialized fire occurrence data as an input for fire risk modelling by using a kernel approach to interpolate historic fire observations.

The main objective of the current study is to assess the influence of the inclusion of several spectral indices on the performance of static, spatially explicit, logistic regression models of fire occurrence probability. We aim to test whether there is an index, or index family, more suitable for model development. As spectral indices account for certain vegetation characteristics (such as biomass, water content, fuel structure and health), we hypothesize that their inclusion will improve model sensitivity to particular spatial situations, not adequately described by other landscape variables. Since vegetation pattern not only change in space but also in time, a multi-temporal approach was followed, considering both time-series of spectral indices and recent fire history. Furthermore, the approach proposed intends to give answer to three specific management questions: (1) can we develop a methodology for modelling fire occurrence probability using accessible spatial information, easily applicable for other places or time periods?; (2) which are the more important predictors (vegetation status, topography, accessibility and landscape structure) when dealing with fire occurrence in the study site?; (3) can our modelling efforts draw the spatial pattern of fire-proneness in the study area?, is this pattern consistent over time?

\section{Data and methods}

\subsection{Study area}

Our study area is the Natural Park of Lago de Sanabria, in north-western Spain (see Fig. 1). The Park covers about 23,000 ha, with elevations ranging from 900 to $2100 \mathrm{~m}$ above sea level and moderate to steep relief. The main economic activities are cattle grazing and the growing tourist industry which has developed recently. The landscape, located along a climatic and altitudinal gradient, has a heterogeneous and patchy pattern mainly as a consequence of the frequent fire events, the agriculture and the cattle grazing, which are interlinked. Two main zones can be defined within the park: (1) woodlots dominated by Quercus pyrenaica, riverside forest communities and mixed shrubland (Erica spp., Calluna vulgaris, Cytisus scoparius and Genista spp.) surrounding a glacial freshwater lake, at elevations ranging from 900 to $1300 \mathrm{~m}$. Most of the local population lives in this zone and small agricultural fields are located near towns. (2) At the highest elevations on steep topography, the matrix is composed of a fire adapted shrubland community, dominated by Erica australis and C. vulgaris. Chamaespartium tridentatum and Halimium alyssoides are also very frequent. This community occurs in different regeneration stages and has been identified by the European Union Habitats Directive (92/43/EEC) as a natural habitat type of community interest. Other communities are also present, consisting mainly of mountain grasslands.

Fire events occur very frequently during early spring (midlate March) and summer (July to late September). Although it was declared a protected area in 1990, fire recurrence has not decreased (Consejería de Medio Ambiente de la Junta de 


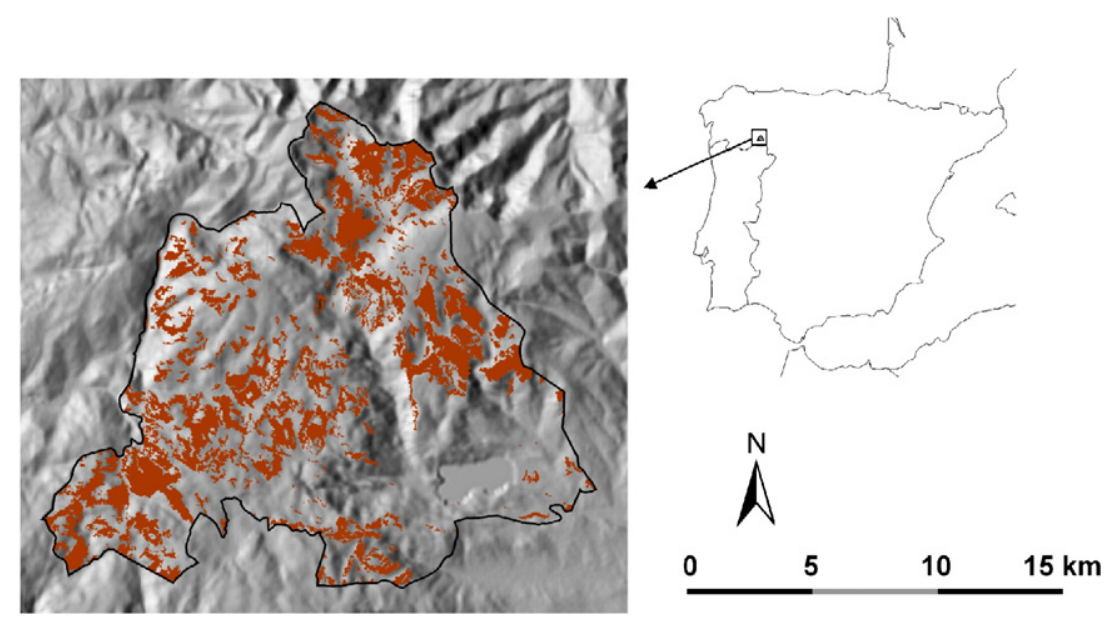

Fig. 1. Location of study site showing illumination model and heathland vegetation patches (landscape matrix and most fire-prone unit).

Castilla y León, 2002) and is identified as the main problem for wildlife managers. Fire ignition is attributed mainly to the local population (about $90 \%$, Gutierrez, pers. com.), which has been using fire for centuries to manage vegetation. Although legal regulations explicitly ban this kind of practice, and social and technical programs have been undertaken to improve the situation and to avoid these practices, fire recurrence has not decreased. Furthermore, changing agricultural policies, an ageing population and the growth of tourism activities have lead to agricultural land abandonment, and finally to an increase in vegetation biomass and fuel layer continuity. These processes create a positive feed-back dynamic which favours fire recurrence and expansion.

\subsection{Environmental variables}

Maps of burned areas were derived from Landsat imagery by means of the differenced Normalized Burned Ratio (dNBR index; Key \& Benson, 1999) for the study site within the period of 1992-2002 (see Lozano et al., 2005 for a detailed description of the followed methodology). Minimum surface for detection was established in $5 \mathrm{ha}$, and maps yielded an overall accuracy of $88.39 \%$, commission error of $10.09 \%$ and omission error of $14.37 \%$. In the current study, those maps of burned areas were used as a data source to generate the binary dependent variable: fire occurrence (1) or no-occurrence (0). The local population usually decided where and when to burn based on vegetation status (biomass, height, moisture, structure, etc.), physical features and accessibility of the selected zones. Two kinds of predictors were therefore used for fire occurrence modelling. Firstly, spectral indices account for the yearly changing vegetation characteristics. Fire occurrence history in the preceding years was considered as a complementary predictor. Secondly, topographic variables derived from the DEM and linear features maps were used to characterize the landscape features that are static and time-independent (on a yearly time-scale) and may affect fire occurrence. All predictors were rasterized with a resolution of $30 \mathrm{~m}$ (Table 1).

Vegetation recovery after fire is rapid in this region because of high water availability and the extensive presence of fire adapted communities (Calvo et al., 2002a). Moreover, fire regime is characterized by a high occurrence and recurrence (36\% of the Natural Park was burned in $1992-2002$, and $20 \%$ of these sites were burned more than once). As a consequence of a research undertaken in the site about vegetation regeneration and fire recurrence dynamics (Lozano et al., 2005), besides the

Table 1

Twenty-four environmental predictors used to characterize fire occurrence

\begin{tabular}{|c|c|}
\hline Code & Predictor description \\
\hline \multicolumn{2}{|c|}{ "Non-changing landscape variables" at the temporal scale of the study (yearly) } \\
\hline Alt & Altitude (m) \\
\hline Slope & Slope (degrees) \\
\hline Mean_il & $\begin{array}{l}\text { Average illumination parameter values (no unit, values range: }-1 \text { to } \\
\text { 1) for June } 1 \text { st, August } 1 \text { st and October } 1 \text { st at midday (solar time) }\end{array}$ \\
\hline Heat & Heat Load Index (no unit) \\
\hline Dis_path & Distance to the nearest path $(\mathrm{m})$ \\
\hline Dis_build & Distance to the nearest building $(\mathrm{m})$ \\
\hline Heath & $\begin{array}{l}\text { Frequency ( } 0 \text { to } 1) \text { of heathland in a } 7 \times 7 \text { kernel (dominated by } \\
\text { Erica spp.) }\end{array}$ \\
\hline Shrub & $\begin{array}{l}\text { Frequency ( } 0 \text { to } 1) \text { of other shrublands in a } 7 \times 7 \text { kernel (dominated } \\
\text { by Cytisus scoparius and Genista } \text { spp.) }\end{array}$ \\
\hline You_for & Frequency ( 0 to 1$)$ of young forest vegetation type in a $7 \times 7$ kernel \\
\hline
\end{tabular}

"Changing landscape variables" at the temporal scale of the study (yearly)

Last fire Number of years since the last fire event in the last three years

NBR1 NBR (Normalized Burned Ratio) index value for the year before

NBR4 NBR index value four years before

NDMI1 NDMI (Normalized Difference Moisture Index) index value for the year before

NDMI4 NDMI index value four years before

NDVI1 NDVI (Normalized Difference Vegetation Index) index value for the year before

NDVI2 NDVI index value two years before

NDVI3 NDVI index value three years before

NDVI4 NDVI index value four years before

TCW1 TCW (Tasseled Cap Wetness) index value for the year before

TCW4 TCW index value four years before

TCG1 TCG (Tasseled Cap Greenness) index value for the year before

TCG2 TCG index value two years before

TCG3 TCG index value three years before

TCG4 TCG index value four years before

All spectral indices were multiplied by 100 . NBR2, NBR3, TCW2, TCW3, NDMI2 and NDMI3 were explored but not included because of correlation analysis results. 
knowledge of local wildlife managers (Gutiérrez, pers. com.), we concluded that the assessment of the four previous years to a fire event can provide significant information when dealing with fire occurrence probability. Therefore, in order to assess vegetation pattern and change, we calculated several spectral indices for the 1992-2002 period from the corrected (radiometric, atmospheric and topographic corrections were undertaken; see Lozano et al., 2005 for a detailed description) and normalized (based on pseudo-invariant features) Landsat TM and Landsat ETM+images: NDVI (Eq. (1)), NDMI (Eq. (2)), NBR (Eq. (3)) and Tasseled Cap Greenness (TCG) and Wetness (TCW). Landsat data, one image per year, were collected at the end of the burning season, in August or September.

$$
\begin{aligned}
\mathrm{NDVI} & =(\mathrm{NIR}-R) /(\mathrm{NIR}+R) ; \mathrm{NDVI} \\
& =(\mathrm{TM} 4-\mathrm{TM} 3) /(\mathrm{TM} 4+\mathrm{TM} 3)
\end{aligned}
$$

$$
\begin{aligned}
\mathrm{NDMI} & =(\mathrm{NIR}-\mathrm{SWIR}) /(\mathrm{NIR}+\mathrm{SWIR}) ; \mathrm{NDMI} \\
& =(\mathrm{TM} 4-\mathrm{TM} 5) /(\mathrm{TM} 4+\mathrm{TM} 5)
\end{aligned}
$$

$$
\begin{aligned}
\mathrm{NBR} & =(\mathrm{NIR}-\mathrm{MIR}) /(\mathrm{NIR}+\mathrm{MIR}) ; \mathrm{NBR} \\
& =(\mathrm{TM} 4-\mathrm{TM} 7) /(\mathrm{TM} 4+\mathrm{TM} 7)
\end{aligned}
$$

Where NIR stands for near-infrared, R for red, SWIR for shortwave-infrared, MIR for mid-infrared and TMx for the different channels of the Landsat TM and ETM+imagery.

These spectral indices can be grouped as follows: vegetation indices (NDVI and TCG), moisture or wetness indices (NDMI and TCW) and fire-related indices (NBR). Two different index structures can also be identified: (i) those using all image channels (Tasseled Cap Transformation) and (ii) those calculated as a ratio of two image channels. Using the burned areas maps, layers showing fire occurrence in the last three years (the period elapsed between the first year with available data, 1992, and the initial assessment year, 1995) were generated to account for the recent fire history. A new variable (Last_fire, Table 1) was then derived accounting for the number of years since the last fire event in the last three years.

Non-changing landscape features, at the temporal study scale, were obtained from the DEM (spatial resolution $30 \mathrm{~m}$, derived from a digital cartography of $10 \mathrm{~m}$ of equidistance between isolines) and vector thematic cartography (scale 1:10,000). Using the DEM, the following predictors were generated: altitude, slope, illumination parameter (Riaño et al., 2003) and Heat Load Index (McCune \& Keon, 2002). Since most of the fires are caused by humans, accessibility is an important factor influencing fire occurrence. Therefore, the following predictors were considered: distance to the nearest path, village or isolated building. Although vegetation biomass and features change between years and within each year, vegetation types change at a longer temporal scale, typically several decades, in the study zone (Calvo et al., 2002b). From detailed habitat mapping (Junta de Castilla y León \& Universidad de Salamanca, 2002), generated under the guidelines of the 92/43/CEE European Directive, we created an integrated vegetation type cartography.
Original classes were reclassified into less detailed and more meaningful classes for the current purpose. The percentage of heathland, other shrublands and young forests (the three classes most affected by fire) was measured as a context variable with a kernel of $7 \times 7$ pixels. The kernel size was selected based on the minimum fire scar size detected by the burned area maps ( $5 \mathrm{ha})$.

\subsection{Sampling method}

A spatial database was created to develop and validate the models. It was created by a sampling methodology based on random points. Since fire patterns may change between years, we undertook multi-temporal sampling, so that scars burned in the period 1995-2002 (initial year was determined by the first available Landsat image - 1991 - for spectral indices calculation) were used. Every year was equally represented in the database. Points were located throughout the study area, excluding lakes and other water bodies. Sampling size consisted of 48000 points, half of which were not burned in this period and the other half were burned. Two subsets were defined within the database according to the considered years: (i) 1995-1999 data for models development ( $75 \%$ of the data) and inner validation (12.5\% of the data) (ii) 2000-2002 data for independent validation (12.5\% of the data) to test the predictive capabilities of the models on years not considered in their development.

\subsection{Data analysis}

A pool of 24 variables related to vegetation status, topography, accessibility to humans and fire history was used for statistical analysis (Table 1). We used the pairwise Spearman coefficient for identifying possible correlation between variables (threshold $=0.7$ ). Then, as an exploratory assessment, we compared the mean values for the environmental variables discriminating between burned and un-burned pixels using the univariate non-parametric Mann-Whitney test ( $U$-test) for independent groups.

Subsequently, we ran logistic regression analyses using different sets of variables to discriminate between burned and un-burned points. Since the main objective of the current study is to test the performance of different spectral indices for fire occurrence modelling, five different pools of independent predictors were defined (Table 2) with regard to the applied

Table 2

Sets of predictors defined for regression analysis (see Table 1 for meaning of codes)

\begin{tabular}{ll}
\hline $\begin{array}{l}\text { Reg. } \\
\text { code }\end{array}$ & Predictors \\
\hline No-index & $\begin{array}{l}\text { Alt, Slope, Mean_il, Heat, Dis_path, Dis_build, Heath, Shrub, } \\
\text { You_for } \\
\text { NBR }\end{array}$ \\
NBR1, NBR4, No-index \\
NDVI & NDVI1, NDVI2, NDVI3, NDVI4, No-index \\
TCW & NDMI1, NDMI4, No-index \\
TCG & TCW1, TCW4, No-index \\
\hline
\end{tabular}


Table 3

Comparison between predictor values for burned and un-burned points

\begin{tabular}{|c|c|c|c|c|}
\hline \multirow[t]{2}{*}{ CODE } & \multicolumn{2}{|c|}{ Un-burned $(\mathrm{n}=10,650)$} & \multicolumn{2}{|c|}{ Burned $(n=10,650)$} \\
\hline & $\mathrm{X}$ & $\mathrm{SD}$ & $\mathrm{X}$ & SD \\
\hline Alt & 1574.74 & 249.28 & 1631.07 & 200.83 \\
\hline Slope & 11.29 & 7.69 & 14.10 & 7.01 \\
\hline Mean_il & 0.83 & 0.09 & 0.85 & 0.08 \\
\hline Heat & 8648.96 & 977.59 & 8935.19 & 902.49 \\
\hline Dis_path & 431.96 & 415.30 & 567.93 & 472.44 \\
\hline Dis_build & 952.44 & 721.35 & 1259.31 & 696.70 \\
\hline Heath & 0.22 & 0.29 & 0.40 & 0.37 \\
\hline Shrub & 0.38 & 0.33 & 0.33 & 0.33 \\
\hline You_for & 0.06 & 0.16 & 0.07 & 0.18 \\
\hline Last_fire & 0.02 & 0.21 & 0.05 & 0.38 \\
\hline NBR1 & 34.28 & 16.68 & 41.16 & 13.28 \\
\hline NBR4 & 31.20 & 18.37 & 34.81 & 15.38 \\
\hline NDMI1 & 11.63 & 13.89 & 17.41 & 11.58 \\
\hline NDMI4 & 10.08 & 14.88 & 13.83 & 12.65 \\
\hline NDVI1 & 61.39 & 10.71 & 64.36 & 7.65 \\
\hline NDVI2 & 62.20 & 10.67 & 63.74 & 8.57 \\
\hline NDVI3 & 61.10 & 10.50 & 62.08 & 8.08 \\
\hline NDVI4 & 60.44 & 11.01 & 61.69 & 8.85 \\
\hline TCW1 & -5.92 & 4.17 & -3.96 & 3.57 \\
\hline TCW4 & -6.11 & 4.14 & -4.94 & 3.55 \\
\hline TCG1 & 13.55 & 5.16 & 13.88 & 4.05 \\
\hline TCG2 & 13.50 & 5.00 & 13.31 & 3.81 \\
\hline TCG3 & 12.88 & 4.87 & 12.73 & 3.67 \\
\hline TCG4 & 12.33 & 5.04 & 12.30 & 3.93 \\
\hline
\end{tabular}

Mean value $(X)$ and standard deviation (SD) are shown.

indices (NBR, NDVI, NDMI, TCW, TCG). Another pool (Noindex) with no spectral indices was included as a control to test their influence on the performance of the final model. In order to account for possible relationships between those variables, bivariate interactions were considered (computed as the product of two predictors). The analysis begins with a full model per each pool (including all the variables and its interactions). Then, variables were eliminated from the initial model in an iterative process, using a backwards stepwise procedure. At each step the significance of the variables included in the initial model was tested, and those being non-significant (significance level $<1 \%$ ) were eliminated. Moreover, to make the final models more parsimonious, we only retained variables that contributed more than $1 \%$ to fire occurrence explanation, assessed by means of the Wald statistic (Harrel, 2001). The regression assessment described above was run twice for each predictor pool, with and without consideration of interactions.

Table 4

Area under the ROC curve and number of variables included for each model

\begin{tabular}{llllll}
\hline Model & \multicolumn{2}{l}{$\begin{array}{l}\text { No interactions } \\
\text { considered }\end{array}$} & & \multicolumn{2}{l}{ Considering double interactions } \\
\cline { 2 - 3 } \cline { 5 - 6 } & ROC & Variables & & ROC & Variables+interactions \\
\hline NBR & 0.7781 & 11 & & 0.8481 & 21 \\
NDMI & 0.7761 & 11 & & 0.8404 & 21 \\
NDVI & 0.7711 & 11 & & 0.8438 & 25 \\
TCW & 0.7784 & 7 & & 0.8471 & 21 \\
TCG & 0.7575 & 9 & & 0.8178 & 21 \\
No-index & 0.7520 & 7 & 0.8152 & 20 \\
\hline
\end{tabular}

Table 5

Average of the probability medians for burned and un-burned points of each model considered

\begin{tabular}{lllllllll}
\hline \multirow{2}{*}{ Model } & \multicolumn{1}{l}{$1995-1999$} & & & $2000-2002$ & & & $1995-2002$ & \\
\cline { 2 - 3 } & Un-burned & Burned & & Un-burned & Burned & & Un-burned & Burned \\
\hline NBR & 0.31 & 0.69 & & 0.33 & 0.52 & & 0.32 & 0.62 \\
NDVI & 0.32 & 0.68 & & 0.35 & 0.50 & & 0.33 & 0.60 \\
TCW & 0.31 & 0.70 & & 0.31 & 0.46 & & 0.31 & 0.60 \\
No-index & 0.37 & 0.66 & & 0.37 & 0.47 & & 0.37 & 0.58 \\
\hline
\end{tabular}

First period (1995-1999) data were used for the development and internal validation of models algorithms. Second period (2000-2002) data were used for independent validation purposes.

Model fit was assessed using the Area Under the Curve (AUC) obtained by the Receiver-Operating Characteristic plot method (ROC-plot; Beck \& Shultz, 1986; Fielding \& Bell, 1997; Stephens \& Finney, 2002), which is a convenient measure that does not require a threshold for presence and absence to be set (Zweig \& Campbell, 1993) and mitigates artefactual effects (McPherson et al., 2004). This curve shows how the fraction false positive varies for varying fraction false negatives. All data were analysed using SPSS 13 (SPSS, 2004).

\subsection{Spatial models}

We used the algorithms obtained by the logistic regression assessment to create maps of fire occurrence probability for each year in the period from 1995 to 2002. In order to simplify further steps, we retained one model per index family (decision was based on the validation results). Optimal cut-off values were calculated for each model (Brito et al., 1999; Pereira \& Itami, 1991) to create boolean maps, identifying pixel at risk of fire. For each year, a new integrated model was derived from the sum of the individual boolean maps. Those maps allowed the outlining of the most fire-prone areas and the assessment of their spatial pattern and its temporal evolution.

The spatial models generated were evaluated by means of inner and independent validation sets. This ensures a reliable validation of the models and assessment of their predictive capabilities under new conditions. Validation assessment had

Table 6

Accuracy of burned points classification and errors for boolean maps

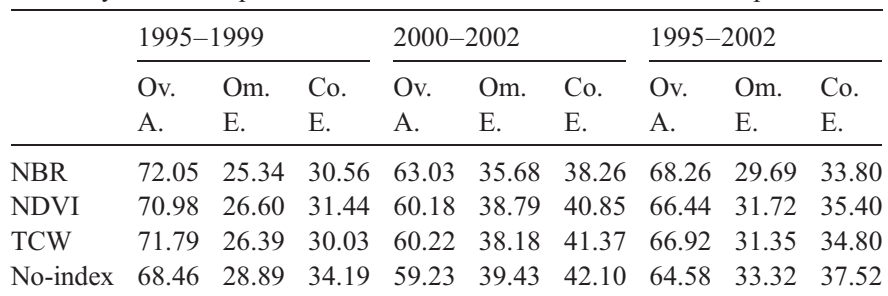

Values are expressed as percentages. First period (1995-1999) data were used for development and internal validation of models algorithms. Second period (2000-2002) data were used for independent validation purposes.

Ov. A: overall accuracy.

Om. E.: omission error.

Co. E.: commission error. 
Table 7

Distribution of validation points within the classes of the integrated models (classes I. M.)

\begin{tabular}{|c|c|c|c|c|c|c|}
\hline \multirow{2}{*}{$\begin{array}{l}\text { Classes } \\
\text { I.M. }\end{array}$} & \multicolumn{2}{|l|}{ 1995-1999 } & \multicolumn{2}{|l|}{$2000-2002$} & \multicolumn{2}{|l|}{ 1995-2002 } \\
\hline & Un-burned & Burned & Un-burned & Burned & Un-burned & Burned \\
\hline 0 & 52.43 & 14.37 & 40.32 & 21.29 & 47.34 & 17.28 \\
\hline 1 & 11.96 & 07.13 & 14.10 & 9.29 & 12.86 & 8.04 \\
\hline 2 & 10.06 & 09.00 & 11.68 & 12.44 & 10.74 & 10.45 \\
\hline 3 & 08.04 & 10.35 & 10.46 & 14.14 & 09.06 & 11.95 \\
\hline 4 & 17.51 & 59.15 & 23.43 & 42.83 & 20.00 & 52.29 \\
\hline
\end{tabular}

Those models are obtained as the sum of the four boolean maps (NBR, NDVI, TCW and No-ind) derived for each year, so that class 4 includes pixels recognized as burn by all considered models whereas class 0 includes those pixels not identified as burn by any of the four models. Values are expressed as percentages. First period (1995-1999) data were used for development and internal validation of model algorithms. Second period (2000-2002) data were used for independent validation purposes.

two targets: continuous probability models (analysis based on the medians of the fire occurrence probability of burn and unburn pixels) and boolean models.

\section{Results}

For every spectral index, except for vegetation indices (NDVI and TCG), correlation analysis excluded all possible time combinations except those formed by the value of the previous year and the four preceding years. Distance to the nearest village was no longer considered since it showed correlation with altitude, and accessibility was already assessed by means of other variables (Dis_path and Dis_build) included in the analysis. No other pair of variables showed correlation.

\subsection{Burned area characteristics}

All variables included in the univariate analysis showed significant differences $(p<0.01)$ between burned and unburned points (Table 3 ). Burned points were located at higher altitude and slope and received more solar radiation. Distances to infrastructures were higher for these points, which also showed a higher frequency of heathland in the surroundings and a lower frequency of other shrublands than un-burned points. Values of the spectral indices obtained the year before the fire event were higher for burned points in all the cases. However, TCG did not show that difference and had a lower explanatory power in terms of fire occurrence.

\subsection{Regression models}

AUC-ROC values varied from 0.75 to 0.85 for all models (Table 4) indicating good overall model fit (Stephens \& Finney,
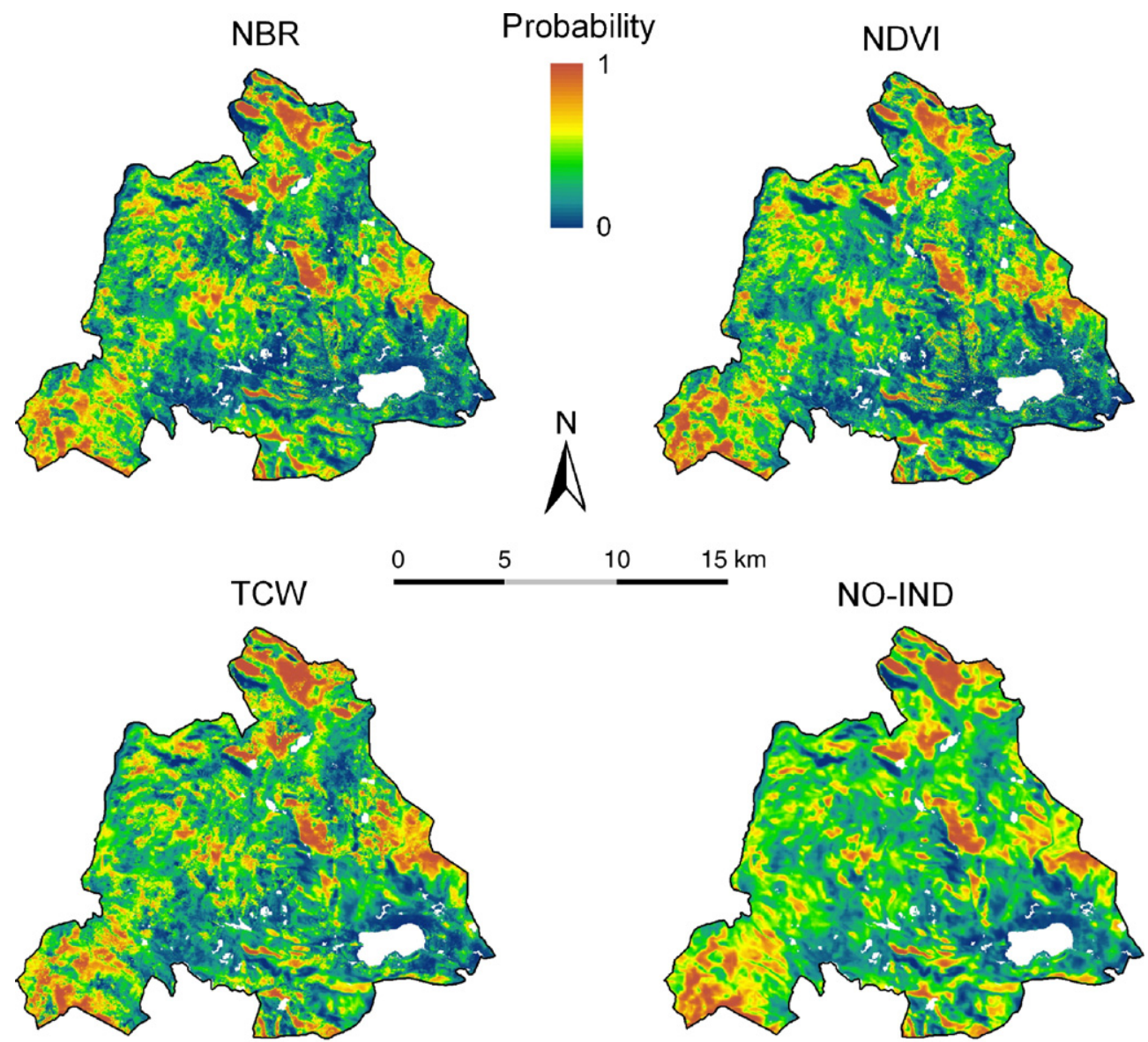

Fig. 2. Example of a continuous probability model of fire occurrence for the study area in 1997. 


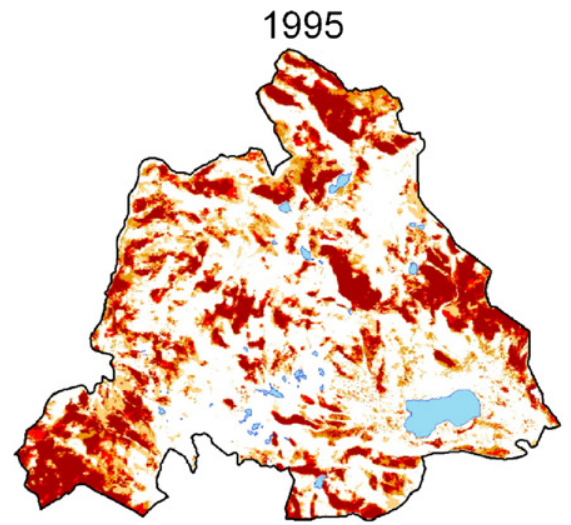

Identified as
burned by
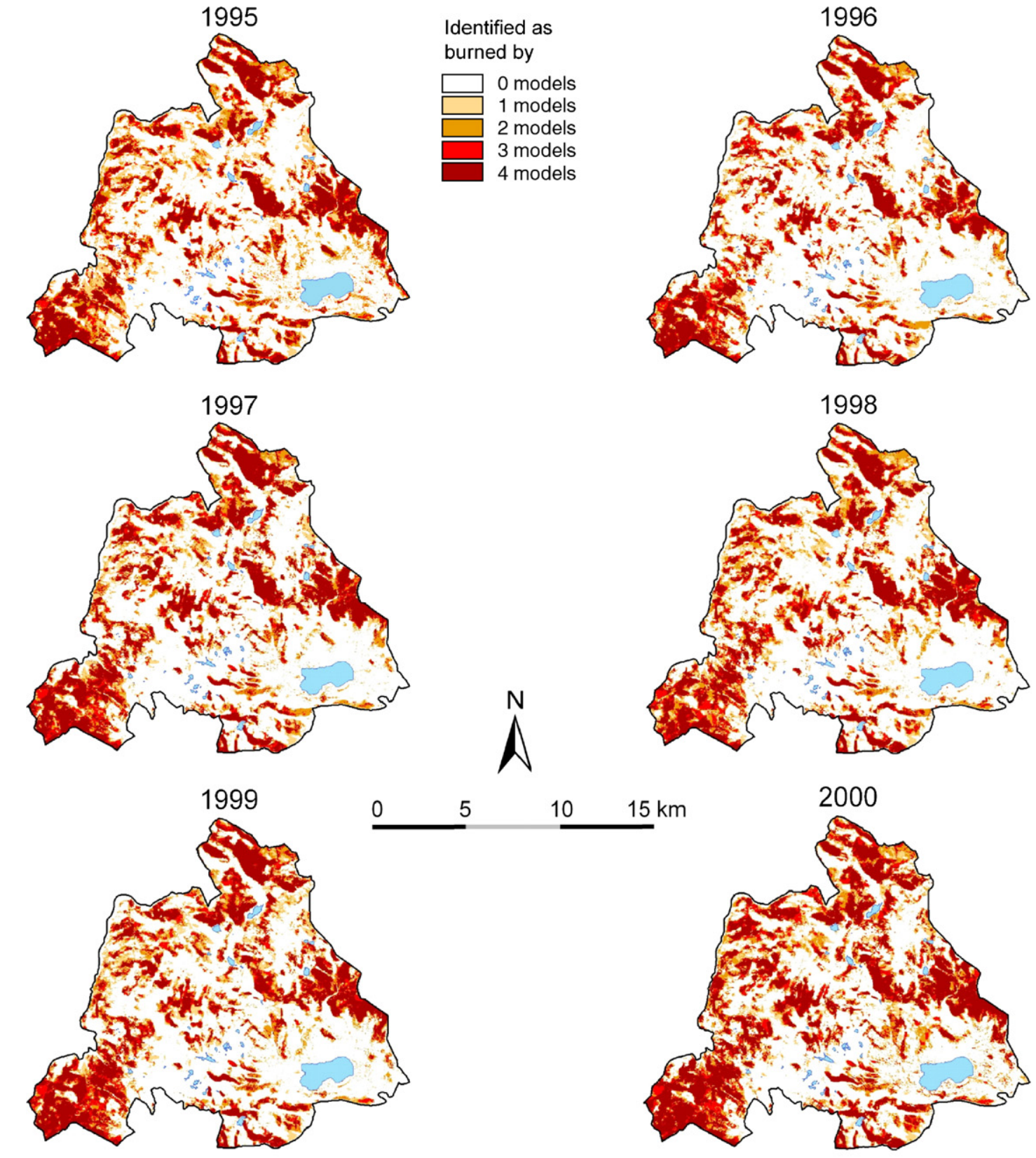

$15 \mathrm{~km}$
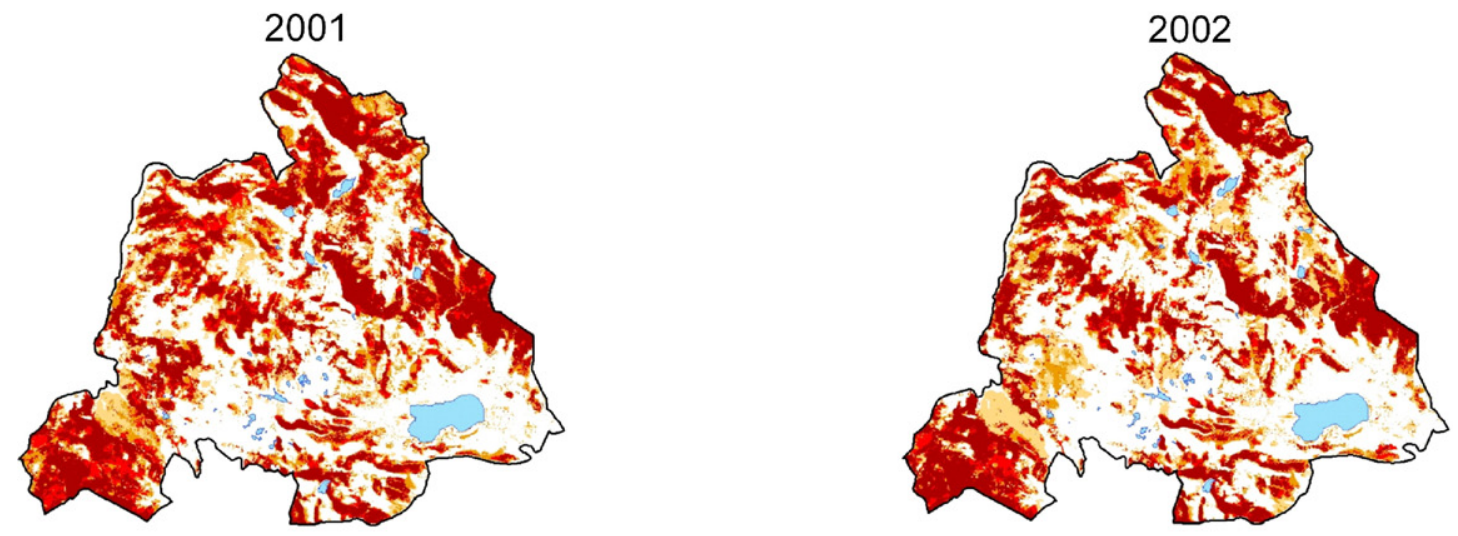

Fig. 3. Integrated models (sum of the four boolean maps calculated for each year) for the study period. The core areas identified by all models are surrounded by buffer zones identifying pixels with particular spatial features. The areas most at risk of fire (core areas) are then identified. 
2002), although those including interactions between predictors generated higher values. In both cases, NBR and TCW models yielded the best results, but NDMI and NDVI showed similar AUC-ROC values, whereas TCG and No-index models performed worst. For models without interactions, slope had the highest explanatory capability values; heathland frequency was also highly significant, while the spectral index value in the previous year (NBR1, NDVI1, etc) was also explicative. However, when considering interactions between variables, distance to the nearest path and its interaction with the Heat Load Index were identified as the strongest explanatory variables; although significantly lower than these variables, slope also showed high explanatory values.

We focused only on the most discriminative models, those including interactions, to simplify further steps. From the retained models, only four were taken into account for further assessment: NBR representing fire-related indices, NDVI representing vegetation indices, TCW representing moisture indices and Noindex in order to test the importance of including spectral indices. NDMI was taken out because it performed slightly worst than $\mathrm{TCW}$, the other moisture index, and TCG because of its poor performance.

Validation analysis concluded the better ability of models based on spectral indices when assessing fire occurrence probability. Table 5 shows the average of the probability medians for burned and un-burned points for each retained model. Medians were all similar, except for No-index, which generated less coherent values. As expected, model performance was better for the years used to develop the models than for the years used in independent validation. These results are consistent with the distribution of probability frequencies for the validation set. It must be emphasised that, although TCW generated the best results for the model development period, it showed the worst predictive power.

Classification accuracy and errors for boolean maps are shown in Table 6 NBR generated the best results and No-index the worst. Accuracy for the independent validation years was lower, as expected, but the same conclusions can be made. Finally, we carried out a validation test for the integrated models (Fig. 3) predicting fire occurrence. Most points were correctly identified by all the models (Table 7). Again, independent validation of the models generated the worst results, especially when predicting the existence of fire. This is in accordance with the results described above.

\subsection{Spatial models}

Three different types of spatial models were derived from the analysis: continuous values of fire occurrence probability (Fig. 2), boolean maps and annual integrated models (sum of the four single boolean maps for each year) (Fig. 3). In most cases, zones with high elevations, steep topography and mostly covered by heathland communities were identified as at risk of burning. From a visual evaluation of the temporal evolution of all the models, it was concluded that: (i) the existence of fire in the previous year conditioned risk patterns, and (ii) models including spectral indices have a fine-grained pattern (more spatially detailed).
However, No-index models showed coarse-grained patterns (see Figs. 2 and 3).

Integrated models (Fig. 3) were computed for each year. Pixels identified as burned by all four models had a similar and stable spatial pattern for all the years considered, identifying most fire-prone zones that could be defined as core areas of fire risk. Other classes, formed by pixels identified as burned by one, two or three models, were usually located around those core areas and their extensions and shapes were more timedependent. Frequencies of the classes of the integrated models were very similar for all of the years considered, including those used in independent validation. Only the model corresponding to 2001 did not support this assertion.

\section{Discussion}

\subsection{Spectral indices}

Maps of fire risk derived from the index-based models showed more detailed spatial information, a much finer-grained pattern. It is likely because of their better recognition of temporal vegetation changes and spatial heterogeneity, leading to a more accurate result. However, spatial pattern derived from the No-index models can be interpreted as the structural fireproneness of the studied landscape, based on topographic variables, accessibility, fire history and vegetation types, and is hence almost static. In this sense, Rollings et al. (2004) also found that the inclusion of biomass and/or vegetation structure by means of remotely sensed data provides improved recognition of pre-fire conditions.

Overall, there is no index family showing a better performance than others when modelling fire occurrence probability in the study site. NBR showed slightly better results. It should be highlighted that, although this index was applied to produce the fire maps, the methodology applied was based on the change in index value before and after the fire event (dNBR), comparing two consecutive images. Conversely, to define the fire occurrence probability model, only the value before the fire (NBR) was considered, and therefore it should be identified as a different variable. It could be argued that, if the methodology applied for burned scars mapping improved the performance of the NBR-based models, then the best discrimination between burned and un-burned points based on the NBR1 value was expected. However, the comparison of indices values for burned and un-burned sampling points for the year before the fire (Table 3), yielded higher relative differences for the moisture indices (NDMI, TCW) than for NBR. While NBR is commonly used as the index pre- and post-fire difference, our results suggest that it also characterizes vegetation fire-proneness before the event takes place.

Indices emphasising SWIR and/or MIR wavelengths in their calculation (NBR, TCW and NDMI) yielded good results. Although the biophysical interpretation of indices that use the SWIR and MIR bands is more problematic than indices that use only red and NIR bands (Wilson \& Sader, 2002), they seem to account for moisture content in vegetation and soil. They have been also linked with tree density and basal area (Cocke et al., 
2005), stand age and vegetation structure (Fiorella \& Ripple, 1993) and state (Wilson \& Sader, 2002). All these factors are crucial when determining the fire risk and seem to be partially included in the models by the indices. Moreover, SWIR and MIR wavelengths penetrate thin clouds and smoke better than visible bands, with MIR to the greatest degree since its wavelengths are larger than most water vapour and smoke particles (Avery \& Berlin, 1992).

TCW-based models obtained the best validation results for the model development period, probably because the index is a linear combination of all spectral channels and, therefore, it accounts for the visible spectral region, not considered by NBR and NDMI. However, those models showed the worst results for the independent validation. This could be explained by its high internal heterogeneity (caused by the inclusion of all bands), which can be increased by changes in vegetation and soil features between years.

Only TCG did not improve the results of the models and, therefore, appears not to adequately account for vegetation characteristics related to the probability of fire occurrence. In contrast, Rollings et al. (2004) followed a similar approach and found Kauth-Thomas Greenness (similar to TCG) to be an important predictor when mapping fuels and fire regime. This difference could take place because forest was the main burn vegetation type in their study site, whereas heathland is the most affected type in the current study site.

The approach adopted, based on an assessment of conditions during preceding years, has proved to be valuable. Although the fire history variable was not selected for most of the models because of its poor explanatory capabilities, spectral indices appear to add information about fire history, since biomass loss related to fire events drastically affects index values. Further research is needed in order to define a more meaningful variable accounting for fire history. Models combining both assessment of current circumstances (mainly fuel status and fire weather) and past fire events appear likely to achieve promising results and further research on this topic is required.

\subsection{Models assessment}

ROC values were slightly higher than those obtained by Alencar et al. (2004) when modelling the occurrence of understorey fires in the Eastern Amazonian. Overall accuracy of all the boolean maps $(65-70 \%)$ was similar to the value achieved by the model put forward by Rollings et al. (2004) to map fire intervals. Nevertheless, in all the cases, classification accuracy decreased by about $10 \%$ when comparing models derived for the development period and the independent validation period. Worsening results such as these are also observed when validating continuous probability models. This is likely to happen because the very patchy landscape pattern characterizing the study zone poses a strong drawback for the performance of the models. Best validation results were yielded by models considering interactions between variables, which included more variables (Table 4). Although the simplest model is the best at the most times, we looked for the algorithm describing most accurately the fire occurrence probability in our study site, so that it could be applied in wildlife management. Thus, produced models are applicable only for the study site, but the followed methodology could be applied in other areas.

Slope was the most explanatory variable in most of the models using single variables. This is likely to happen because it is a major driver of fire spread throughout the landscape and it is also strongly related to accessibility and vegetation type. The inclusion of topographic variables is strongly recommended when modelling fire occurrence, as was also concluded by Preisler et al. (2004). The frequency of heathlands surrounding a given pixel was also important, which is in accordance with previous knowledge about the most fire-prone vegetation communities in the region (Calvo et al., 2002a). Models using interactions between variables performed better since they account for particular spatial situations. The most meaningful interaction was between the distance to paths and the solar energy received by a given pixel (also identified as a crucial variable for fire occurrence by Díaz-Delgado et al., 2004). Distance to the nearest path was greater for burned points, (see Table 3), possibly because, although fires are ignited close to paths, they move uphill towards the mountainous part of the park, where fuel layer is more continuous and accessibility is much poorer for fire fighting teams because of the lower density of paths.

The sums of the four boolean maps calculated for each year (the integrated models) outline the general spatial pattern of fire occurrence, which change only slightly in time. Core areas, with the highest probability of burning, are surrounded by buffer areas, where the vegetation characterization provided by the spectral indices defines different levels of fire risk. This approach can provide a powerful alternative to single-indexbased models when assessing fire risk.

The applied methodology has proved to be valuable for understanding spatial patterns of burning in a given landscape. Nevertheless, the temporal length of the available burned area maps (eleven years) does not allow for medium- or long-term monitoring studies. A longer series of burned area maps is needed if a more in-depth study is to be made about fire regimes.

Particularly low accuracies were observed for year 2001 . Rain and snow were especially heavy that winter, and this probably altered the fire characteristics. This fact suggests that the inclusion of some weather variables could improve the results. Nevertheless, very accurate climatic data, which are not available for the study site, are needed to derive climatic variables with a spatial resolution comparable to variables derived from Landsat imagery.

Imagery sensed at the beginning of the fire season would provide another interesting variable. This would describe vegetation status and biomass more accurately than using data from the previous year, thus indirectly taking into consideration weather conditions during the previous winter and spring. Nevertheless, in zones such as the present study area, where the landscape is patchy and a complex system ultimately drives fire occurrence, high spatial resolution is needed to account for rapidly changing spatial variables. It is anyway a scale matter. 


\subsection{Model applications to fire management}

The availability of maps of fire occurrence probability is of great interest for fire managers and, indirectly, for the whole community involved in managing biodiversity and ecosystems within natural parks. Fire prevention operations, mostly based on mechanical vegetation removal in this study area, are expensive and sometimes very destructive. This methodology provides managers with the best available scientific information about existing or potential vegetation conditions at a landscape scale, and can significantly improve the design of predictive measures. The identification of core areas, where fire risk is especially high, can be directly applied to fire management. Moreover, fire maps obtained by these methods improve knowledge transfer from fire ecologists to fire managers (Rollings et al., 2004).

\section{Conclusions}

Inclusion of spectral indices (with the exception of TCG) improved prediction of fire occurrence. Spectral indices account for particular and site-specific conditions, adding extra information to the basic, structural spatial patterns drawn by models developed without such indices. Overall, no index family showed a better performance than others when modelling fire occurrence probability in the study site, and the integration of the applied indices into a single model showed promising results.

Our methodology uses data that are easily accessible and only information about spatial patterns of fire history is needed to develop the model. Assessment of vegetation conditions and fire history in recent years was meaningful when characterizing fire events. In general terms, two topographic variables (slope and received solar radiation), two distance variables to infrastructures (paths and buildings) and a variable describing vegetation type (heathland frequency) had high explanatory power, in addition to the value of the applied spectral index the year before the fire event. Integration of spatial layers derived from satellite imagery and geographical information using regression analysis is a powerful tool for understanding and managing fire occurrence.

\section{Acknowledgements}

This work was supported by the Spanish Ministry of Education and Science under the research project REN2002-04463-C0201 and its research grant BES-2003-3130 awarded to F. J. Lozano. The authors would like to thank Dr. Díaz-Delgado (CSIC — Estación Biológica de Doñana, Spain), Dr. Kelly (University of California, Berkeley), I. Prieto Sarro (Cartography, University of León, Spain), J. L. Gutierrez (Lago de Sanabria and Surroundings Natural Park, staff) and the anonymous reviewers for their helpful comments and information. We also are grateful to Jose M. Álvarez and Althea Davies for help. Finally we wish to thank the Fire Dept. of the Environmental Section, Junta de Castilla y León, for their support to this study by providing digital geographical data.
Appendix A. Models without interactions obtained by the logistic regression analysis

For all the models $p=0.00$. For each included predictor, the corresponding coefficient in the algorithm and value of the Wald statistic are shown.

\begin{tabular}{|c|c|c|}
\hline $\begin{array}{l}\text { NBR-base } \\
\text { Predictor }\end{array}$ & Coefficient & Wald \\
\hline NBR1 & 0.0457 & 820.93 \\
\hline NBR4 & -0.0108 & 65.10 \\
\hline Slope & 0.0863 & 1255.50 \\
\hline Dis_path & 0.0005 & 175.90 \\
\hline Dis_build & 0.0006 & 507.86 \\
\hline Mean_il & 1.6989 & 34.46 \\
\hline Last_fire & 0.2149 & 14.49 \\
\hline Heat & 0.0003 & 151.53 \\
\hline Heath & 1.9720 & 1048.77 \\
\hline Shrub & 0.9521 & 226.20 \\
\hline You_for & 0.5832 & 28.65 \\
\hline Constant & -8.7003 & 1947.51 \\
\hline \multicolumn{3}{|c|}{ NDVI-based model } \\
\hline Predictor & Coefficient & Wald \\
\hline NDVI1 & 0.0671 & 734.67 \\
\hline NDVI3 & -0.0208 & 83.47 \\
\hline Altitude & 0.0004 & 16.48 \\
\hline Slope & 0.0826 & 1164.48 \\
\hline Dis_path & 0.0004 & 108.52 \\
\hline Dis_build & 0.0005 & 467.13 \\
\hline Mean $\_$il & 1.3821 & 23.40 \\
\hline Heat & 0.0004 & 191.43 \\
\hline Heath & 2.1456 & 1177.72 \\
\hline Shrub & 0.8186 & 167.77 \\
\hline You_for & 0.6057 & 29.00 \\
\hline Constant & -10.8244 & 1500.19 \\
\hline \multicolumn{3}{|c|}{ NDMI-based model } \\
\hline Predictor & Coefficient & Wald \\
\hline NDMI1 & 0.0490 & 710.82 \\
\hline NDMI4 & -0.0084 & 27.30 \\
\hline Slope & 0.0845 & 1213.35 \\
\hline Dis_path & 0.0005 & 183.35 \\
\hline Dis_build & 0.0006 & 508.31 \\
\hline Mean_il & 1.5531 & 29.05 \\
\hline Last_fire & 0.1875 & 11.22 \\
\hline Heat & 0.0003 & 162.56 \\
\hline Heath & 1.9890 & 1072.08 \\
\hline Shrub & 0.9444 & 224.20 \\
\hline You_for & 0.5747 & 27.86 \\
\hline Constant & -7.8937 & 1738.76 \\
\hline \multicolumn{3}{|c|}{ TCW-based model } \\
\hline Predictor & Coefficient & Wald \\
\hline TCW1 & 0.1478 & 1065.60 \\
\hline Slope & 0.0895 & 1434.92 \\
\hline Dis_path & 0.0005 & 178.77 \\
\hline Dis_build & 0.0005 & 461.73 \\
\hline Heat & 0.0005 & 762.46 \\
\hline Brezal & 1.7560 & 998.82 \\
\hline Matorral & 0.7325 & 159.53 \\
\hline Constant & -6.2770 & 1294.99 \\
\hline
\end{tabular}


Appendix A (continued)

\begin{tabular}{lrr}
\hline TCG-based model & & \\
Predictor & Coefficient & \multicolumn{1}{c}{ Wald } \\
\hline TCG1 & 0.0824 & 280.89 \\
TCG2 & -0.0617 & 148.06 \\
Slope & 0.0879 & 1339.19 \\
Dis_path & 0.0003 & 73.30 \\
Dis_build & 0.0005 & 490.37 \\
Heat & 0.0005 & 769.43 \\
Heath & 2.1163 & 1212.08 \\
Shrub & 0.5692 & 82.02 \\
You_for & 0.8262 & 61.06 \\
Constant & -7.2960 & 1629.39 \\
& & \\
NO-INDEX model & & \\
Predictor & Coefficient & Wald \\
\hline Slope & 0.0861 & 1330.63 \\
Dis_path & 0.0003 & 70.18 \\
Dis_build & 0.0005 & 482.14 \\
Heat & 0.0005 & 803.31 \\
Heath & 1.9459 & 1103.82 \\
Shrub & 0.4147 & 50.34 \\
You_for & 0.9251 & 78.46 \\
Constant & -6.8983 & \\
\hline & & \\
& & \\
\hline & & \\
\hline
\end{tabular}

\section{References}

Alencar, A. C., Solórzano, L. A., \& Nepstad, D. C. (2004). Modeling forest understory fires in an Eastern Amazonian Landscape. Ecological Applications, 14(4), 139-149.

Andersen, H. E., McGaughey, R. J., \& Reutebuch, S. E. (2005). Estimating forest canopy fuel parameters using LIDAR data. Remote Sensing of Environment, 94, 441-449.

Avery, T. E., \& Berlin, G. L. (1992). Fundamentals of remote sensing and airphoto interpretation, 5th ed. Upper Saddle River, NJ: Prentice Hall. 472 pp.

Beck, J. B., \& Shultz, E. K. (1986). The use of relative operating characteristics (ROC) curves in test performance evaluation. Archives of Pathology and Laboratory Medicine, 110, 13-20.

Brito, J. C., Crespo, E. G., \& Paulo, O. S. (1999). Modelling wildlife distributions: Logistic multiple regression vs. overlap analysis. Ecography, 22, 251-260.

Brockway, D. G., \& Lewis, C. E. (1997). Long-term effects of dormant-season prescribed fire on plant community diversity, structure and productivity in a longleaf pine wiregrass ecosystem. Forest Ecology and Management, 96, $167-183$.

Calvo, L., Tárrega, R., \& Luis, E. (2002a). The dynamics of Mediterranean shrubs species over 12 years following perturbations. Plant Ecology, 160, $25-42$

Calvo, L., Tárrega, R., \& Luis, E. (2002b). Secondary succession after perturbations in a shrubland community. Acta Oecologica, 23, 393-404.

Cardille, J. A., Ventura, S. J., \& Turner, M. G. (2001). Environmental and social factors influencing wildfires in the Upper Midwest, United States. Ecological Applications, 11(1), 111-127.

Chand, T. R. K., Badarinath, K. V. S., Prasad, V. K., Murthy, M. S. R., Elvidge, C. D., \& Tuttle, B. T. (2006). Monitoring forest fires over the Indian region using Defense Meteorological Satellite Program-Operational Linescan System nighttime satellite data. Remote Sensing of Environment, 103, 165-178.

Chuvieco, E., Cocero, D., Riaño, D., Martín, P., Martínez-Vega, J., de la Riva, J., et al. (2004). Combining NDVI and surface temperature for the estimation of live fuel moisture content in forest fire danger rating. Remote Sensing of the Environment, 92, 322-331.

Clark, L. K. (2000). Pictures at a conflagration: Remote sensing and GIS techniques for mapping and analyzing prescribed fire in the Madrean Archipelago. M.A. thesis, Department of Geography and Regional Development, University of Arizona, Tucson, AZ, 234 pp.
Cocke, A. E., Fulé, P. Z., \& Crouse, J. E. (2005). Comparison of burn severity assessments using differenced normalized burn ratio and ground data. International Journal of Wildland Fire, 14, 189-198.

Consejería de Medio Ambiente de la Junta de Castilla y León (2002). Estadística de Incendios Forestales en Castilla y León. In Junta de Castilla y León (Ed.), Memoria Anual de la Consejería de Medio Ambiente, 2001-2002.

Crist, E. P., \& Cicone, R. C. (1984). A physically-based transformation of Thematic Mapper data — the TM tasseled cap. IEEE Transactions on Geoscience and Remote Sensing, 22, 256-263.

de la Riva, J., Pérez-Cabello, F., Lana-Renault, N., \& Koutsias, N. (2004). Mapping wildfire occurrence at regional scale. Remote Sensing of the Environment, 92, 363-369.

Dennison, P. E., Charoensiri, K., Roberts, D. A., Peterson, S. H., \& Green, R. O. (2006). Wildfire temperature and land cover modeling using hyperspectral data. Remote Sensing of Environment, 100, 212-222.

Díaz-Delgado, R., Lloret, F., \& Pons, X. (2004). Spatial patterns of fire occurrence in Catalonia, NE, Spain. 2004. Landscape Ecology, 19(7), $731-745$.

Díaz-Delgado, R., Lloret, F., Pons, X., \& Terradas, J. (2002). Satellite evidence of decreasing resilience in Mediterranean plant communities after recurrent wildfires. Ecology, 83(8), 2293-2303.

Fielding, A. H., \& Bell, J. F. (1997). A review of methods for the assessment of prediction errors in conservation presence/absence models. Environmental Conservation, 24, 38-49.

Fiorella, M., \& Ripple, W. J. (1993). Determining successional stage of temperate coniferous forests with Landsat satellite data. Photogrammetric Engineering and Remote Sensing, 59, 239-246.

Harrel Jr., F. E. (2001). Regression modeling strategies: Springer-Verlag. ISBN:0387952322.

Jia, G. J., Burke, I. C., Goetz, A. F., Kaufmann, M. R., \& Kindel, B. C. (2006). Assessing spatial patterns of forest fuel using AVIRIS data. Remote Sensing of the Environment, 102, 318-327.

Jin, S., \& Sader, S. A. (2005). Comparison of time series tasseled cap wetness and the normalized difference moisture index in detecting forest disturbances. Remote Sensing of the Environment, 94, 364-372.

Junta de Castilla y León, \& Universidad de Salamanca (2002). In Junta de Castilla y León (Ed.), Cartografía Detallada de Hábitats del Anexo I de la directiva 92/43/CEE a Escala 1:10 000 en el Espacio Natural del Lago de Sanabria y Alrededores.

Justice, C. O., Giglio, L., Korontzi, S., Owens, J., Morisette, J. T., Roy, D., et al. (2002). The MODIS fire products. Remote Sensing of Environment, 83, 244-262.

Key, C. H., \& Benson, N. C. (1999). Measuring and remote sensing of burn severity. In L. F. Neuenschwander \& K. C. Ryan (Eds.), Proceedings Joint Fire Science Conference and Workshop, vol. II (p. 284). Moscow, ID: University of Idaho and International Association of Wildland Fire.

Koutsias, N., \& Karteris, M. (2000). Burned areas mapping using logistic regression modeling of a single post-fire Landsat-5 Thematic Mapper image. International Journal of Remote Sensing, 21(4), 673-687.

Liu, J., Drummond, J. R., Li, Q., Gille, J. C., \& Ziskin, D. C. (2005). Satellite mapping of $\mathrm{CO}$ emission from forest fires in Northwest America using MOPITT measurements. Remote Sensing of Environment, 95, 502-516.

Lloret, F., Calvo, E., Pons, X., \& Díaz-Delgado, R. (2002). Wildfires and landscape patterns of fragmentation in Eastern Iberian peninsula. Landscape Ecology, 17, 745-759.

López, A. S., San-Miguel-Ayanz, J., \& Burgan, R. (2002). Integration of satellite sensor data, fuel type maps and meteorological observations for evaluations of forest fire risk at the pan-European scale. International Journal of Remote Sensing, 23(13), 2713-2719.

López García, M. J., \& Caselles, V. (1991). Mapping burns and natural reforestation using Thematic Mapper data. Geocarto International, 1, $31-37$.

Lozano, F. J., Suárez-Seoane, S., \& de Luis, E. (2005). Vegetation dynamics after fire: opportunities of the combined use of fire detection and ecological indices. A case study in West Spain. In J. De la Riva, F. Pérez-Cabello, \& E. Chuvieco (Eds.), Proceedings of the 5th International Workshop on Remote Sensing and GIS applications to forest fire management: Fire effects assessment (pp. 269-273). Universidad de Zaragoza. 
Mbow, C., Goïta, K., \& Bénié, G. B. (2004). Spectral indices and fire behavior simulation for fire risk assessment in savanna ecosystems. Remote Sensing of the Environment, 91, 1-13.

McCune, B., \& Keon, D. (2002). Equations for potential annual direct incident radiation and heat load. Journal of Vegetation Science, 13, 603-606.

McDonald, A. J., Genmell, F. M., \& Lewis, P. E. (1998). Investigation of the utility of spectral indices for determining information on coniferous forests. Remote Sensing of the Environment, 66, 250-272.

McPherson, J. M., Jetz, W., \& Rogers, D. J. (2004). The effects of species' range size on the accuracy of distribution models: ecological phenomenon or statistical artefact? Journal of Applied Ecology, 4, 811-823.

Patterson, M. W., \& Yool, S. R. (1998). Mapping fire-induced vegetation mortality using Landsat Thematic Mapper data: A comparison of linear transformation techniques. Remote Sensing of the Environment, 65, 132-142.

Pausas, J. G., \& Ramos, J. I. (2004). Landscape pattern, fire regime and vegetation dynamics. A modeling approach. In M. Arianoutsou \& V. P. Papanastasis (Eds.), Ecology, conservation and management of Mediterranean climate ecosystems of the world. Proceedings of MDEDECOS 10th International Conference, Millpress, The Netherlands, Electronic edition.

Pereira, J. M., \& Itami, R. M. (1991). GIS-based habitat modelling using logistic multiple regression: A study of the Mt. Graham red squirrel. Photogrammetric Engineering and Remote Sensing, 57(11), 1475-1486.

Preisler, H. K., Brilllinger, D. R., Burgan, R. E., \& Benoit, J. W. (2004). Probability based models for estimation of wildfire risk. International Journal of Wildland Fire, 13(2), 133-142.

Riaño, D., Chuvieco, E., Salas, J., \& Aguado, I. (2003). Assessment of different topographic corrections in Landsat-TM data for mapping vegetation types. IEEE Transactions on Geoscience and Remote Sensing, 41(5), 1056-1061.

Rollings, M. G., Keane, R. E., \& Parsons, R. A. (2004). Mapping fuels and fire regimes using remote sensing, ecosystem simulation and gradient modeling. Ecological Applications, 14(1), 75-95.

Rouse, J. W., Haas, R. H., Schell, J. A., \& Deering, D. W. (1973). Monitoring vegetation systems in the Great Plains with ERTS, Third ERTS Symposium, NASA SP-351, Vol. 1 (pp. 309-317).
SPSS (2004). SPSS 13.0 command syntax reference.

Stephens, S. L., \& Finney, M. A. (2002). Prescribed fire mortality in Sierra Nevada mixed conifer tree species: Effects of crown damage and forest floor consumption. Forest Ecology and Management, 162, 261-271.

Stroppiana, D., Pinnock, S., \& Gregoire, J. M. (2000). The global fire product: Daily fire occurrence from April 1992 to December 1993 derived from NOAA AVHRR data. International Journal of Remote Sensing, 21, 1279-1288

Terradas, J., Piñol, J., \& Lloret, F. (1998). Risk factors in wildfires along the Mediterranean coast of the Iberian Peninsula. In L. Trabaud (Ed.), Fire Management and landscape ecology. International Association of Wildland Fire, Fairfield (pp. 297-304).

Trabaud, L., Christensen, N. L., \& Gill, A. M. (1993). Historical Biogeography of fire in temperate and Mediterranean ecosystems. In P. J. Crutzen \& J. G. Goldammer (Eds.), Fire in the environment: The ecological, atmospheric and climatic importance of vegetation fires (pp. 277-295). New York, New York, USA: John Wiley \& Sons.

Tucker, C. J. (1979). Red and photographic infrared linear combinations for monitoring vegetation. Remote Sensing of the Environment, 8, 127-150.

Vega García, C., Woodard, P. M., Titus, S. J., Adamowicz, W. L., \& Lee, B. S. (1995). A logit model for predicting the daily occurrence of human caused forest fires. International Journal of Wildland Fire, 5(2), 101-111.

White, J. D., Ryan, K. C., Key, C. C., \& Running, S. W. (1996). Remote sensing of forest fire severity and vegetation recovery. International Journal of Wildland Fire, 6, 125-136.

Wilson, E. H., \& Sader, S. A. (2002). Detection of forest harvest type using multiple dates of Landsat TM imagery. Remote Sensing of Environment, 80, 385-396.

Zweig, M. H., \& Campbell, G. (1993). Receiver-operating characteristic (ROC) plots: A fundamental evaluation tool in clinical medicine. Clinical Chemistry, 39, 561-577. 